\title{
Anything but the truth
}

\section{Joseph Bjelde ${ }^{1}$}

Received: 17 May 2019 / Accepted: 20 April 2020 / Published online: 30 April 2020

() The Author(s) 2020

\begin{abstract}
Fundamental epistemic values are values that best explain some epistemic evaluations. But there are, I argue, no epistemic evaluations which are best explained by positing truth as an epistemic value. So truth is not a fundamental epistemic value.
\end{abstract}

Keywords Value $\cdot$ Truth $\cdot$ Epistemic value $\cdot$ Veritism $\cdot$ Evidentialism

Veritism says that truth is the only fundamental epistemic value. Most of the debate about veritism is about whether there are, in addition to truth, other fundamental epistemic values. I will argue that this is a mistake. Truth is not a fundamental epistemic value at all.

The argument I will present for that claim has the virtue of simplicity. It turns on a relatively uncontroversial axiological framework, on which fundamental values in a given domain best explain the true evaluations in that domain. But, I argue, truth is not the best explainer in the epistemic domain. The argument proceeds in two steps. First, there is a group of epistemic evaluations which would be explained by positing truth as an epistemic value. For instance, evaluations of beliefs as justified are plausibly explained by positing truth as an epistemic value. But those epistemic evaluations are explained at least as well by positing evidential support as an epistemic value. So, while positing truth would explain those evaluations, it does not best explain them. Second, there is a group of evaluations which truth might best explain. For example, truth might best explain why we generally have pro tanto reason to desire true beliefs. But, I will argue, these evaluations are not epistemic. ${ }^{1}$

If the argument works for truth, then it works for accuracy too, ${ }^{2}$ so that in that respect it casts a wide net. But the argument inevitably depends upon some controvertible assumptions, and readers who reject these will fall outside its net. In the last section

\footnotetext{
1 This argument is thus quite different from those considered and responded to in Pritchard (2014).

2 Several recent defenses of veritism are phrased in terms of accuracy rather than than truth, e.g. AhlstromVij and Grimm (2013), Pettigrew (2016), and Sylvan (2018).

$凶 \quad$ Joseph Bjelde joseph.bjelde@hu-berlin.de

1 Institut für Philosophie, Humboldt Universität zu Berlin, Unter den Linden 6, 10099 Berlin, Germany
} 
of the paper, I sketch an account of which readers it should catch. In particular, I argue that the argument should be persuasive to those for whom the boundaries of the epistemic are demarcated by evidence. They should count evidential support as a candidate fundamental epistemic value which is at least as well qualified as truth.

\section{Fundamental epistemic values and best explanations}

By fundamental values, I mean values which are explanatorily fundamental. That is to say that they play a fundamental role in explaining why some set of evaluations are true, where evaluations are broadly conceived to include all claims which say that something is in some way good or bad. To play a fundamental role in those explanations is to figure in the best explanations of the evaluations in question. Thus a fundamental epistemic value will be a value which plays a role in the best explanation of epistemic evaluations.

This account of what it would be to be a fundamental epistemic value is relatively uncontroversial: that is, it is as uncontroversial as accounts of anything so central to philosophy are. ${ }^{3}$ In what follows I will simply assume it, and assume too that the claims I will make about best explanation are clear enough. What is important, for my purposes, is to get a bit clearer than is usually done, in debates about epistemic value, on what it means for a value to be fundamental. Parallel arguments could, I think, be run with a different account of fundamentality.

One important way in which this account of fundamental epistemic value is uncontroversial should be clarified up front. Epistemic values are not the only factors which can figure in the best explananations of epistemic evaluations. So this account does not require that fundamental epistemic values best explain epistemic evaluations on their own; other factors may be indispensable to the best explanations. For instance, even if truth is the only fundamental epistemic value, it will not follow that all true beliefs are equivalently valuable, because some relations to truth might be more valuable than others. More truth-sensitive beliefs, for instance, might be more epistemically valuable than less truth-sensitive beliefs, as might beliefs which manifest respect for the truth or non-belief states which represent a better grasp of the truth than belief. So

\footnotetext{
3 To say that this is relatively uncontroversial is of course not to say that it is correct, and one might well think that other considerations are relevant to being a fundamental value. For instance, gerrymandered properties might better explain but fail to be fundamental, as an anonymous reviewer points out. And it is somewhat common to think that the best explanations of some physical phenomena-human action, or the fact that square pegs won't fit through round holes of equal area - are not best explained in terms of those physical things which are nonetheless fundamental, as another anonymous reviewer points out. But fundamental values seem in this regard unlike fundamental particles, though it is beyond the scope of this paper to try to say how; and the alternatives to truth which I will consider are not gerrymandered, so that neither of those two objections seem promising ways for veritists to go. Still, the point remains, that some veritists might respond to the present argument by rejecting this account of fundamental value. One notable subgroup of those will accept the basic connection between fundamentality and best explanation, but reject the claim that fundamental values are those which uniquely best explain. That matters for the argument here because the argument of the paper leaves open the possibility that the two axiologies it considers might be explanatorily equivalent, and assumes that in that case neither account would correctly identify the fundamental epistemic values. It is clearly open to veritists to dispute that result, and claim that both of the resulting axiologies would be correct, or that something other than best explanation should be used as a tie-breaker in such cases.
} 
this account of fundamental epistemic value leaves significant room for defenses of veritism against common objections, such as the swamping problem.

The use of this account of fundamental epistemic value does, however, importantly depend on which evaluations count as epistemic, and stipulating an answer to this question would be wrongheaded. But it is uncontroversial that typical evaluations of the following forms are epistemic:

"S has justified belief that p"

"S's belief that $p$ is rational"

"S formed her belief that $\mathrm{p}$ on the basis of good evidence"

"S knows p"

Some of these uncontroversially epistemic evaluations are true. Why are they true? That is the question I turn to next.

\section{Explaining epistemic evaluations: not the best}

In one prima facie plausible kind of explanation, the starring role is played by truth. These veritist explanantia will have the following form:

"X bears relation $\mathrm{R}$ to truth" 4

Individual verists may fill out the relations involved in significantly different ways. Very simple veritist explanations of the uncontroversially epistemic evaluations might go as follows:

"S has a justified belief that p" is true (when it is) because S's belief that $\mathrm{p}$ is likely to be true.

"S's belief that $p$ is rational" is true (when it is) because S's belief that $p$ was formed in accordance with methods that are likely to produce true beliefs.

"S formed her belief that $\mathrm{p}$ on the basis of good evidence" is true (when it is) because $\mathrm{S}$ formed her belief that $\mathrm{p}$ on the basis of evidence which makes it likely to be true.

"S knows p" is true (when it is) because S's belief that p tracks the truth.

More sophisticated veritist explanations are not only possible but actual. To take just one recent author, and one kind of explanandum, Sylvan (2018) (p. 403) would explain the explanada about justification in terms of a belief manifesting respect for the truth:

"S has a justified belief that p" is true (when it is) because S's belief that $\mathrm{p}$ manifests strong respect for the accuracy norm, which is that it is correct to believe $\mathrm{P}$ iff $\mathrm{P}$ is true.

\footnotetext{
4 This formulation (as well as the parallel evidentialist formulation below) is intended to be neutral on both the question of whether the cited relation is dyadic or involves further relata. This one is also intended to be neutral on the question whether the relatum is the truth of some proposition, or the mental state of belief in a true proposition.
} 
For the sake of clarity, I'll continue to use the simpler explanations as examples, but nothing will depend on the veritist giving these oversimplified explanations.

Veritist explanations are not the only prima facie plausible explanations of those kinds of evaluations. In another such kind of explanation, the starring role is played by evidential support. These axiological evidentialist explanantia will take the form:

"X bears relation $\mathrm{R}$ to evidential support"

Just as veritism is neutral on which particular explanations of that form are correct, so too is axiological evidentialism. In particular, axiological evidentialists need not give the simplest explanantia of this form, so that they are not committed to evidentialism about justification. That said, the following simple explanations are of the right form, and the simple explanation of explananda about justification will inherit all the plausibility of evidentialism about justification.

"S has a justified belief that p" is true (when it is) because S's belief that $\mathrm{p}$ is supported by S's evidence.

"S's belief that $p$ is rational" is true (when it is) because S's belief that $p$ was formed in accordance with methods that produce evidentially supported beliefs. "S formed her belief that $\mathrm{p}$ on the basis of good evidence" is true (when it is) because $S$ formed her belief that $\mathrm{p}$ on the basis of evidence which supports it.

"S knows p" is true (when it is) because S's true belief that $\mathrm{p}$ is adequately supported by her evidence.

My contention in this section of the paper is that for any given veritist explanans, there will be an evidentialist explanans which explains these explananda no worse than the veritist explanans. The argument is by way of a dilemma, which turns on whether a particular pair of veritist and evidentialist explanantia are predictively equivalent, in the sense that they make the same predictions about which epistemic evaluations will be true. If a given pair is predictively equivalent, then the evidentialist explanans will be no worse than the veritist explanans. If the pair is not predictively equivalent, the evidentialist explanans will often be better, and at any rate no worse, than the veritist explanans. Since these are exhaustive, there will be no pairs in which the veritist explanations are better-at least not when it comes to these uncontroversially epistemic explananda.

Take for example the simple veritist and evidentialist explanations about justified beliefs. If likelihood of truth is simply a matter of evidential support, these simple explanations will be predictively equivalent. They will not be equivalent for all purposes or to everyone, not least because explanation is intensional. But they will be predictively equivalent, because they will count the same token actual and potential beliefs as justified. In this case it is prima facie plausible that the explanations are equally good - though I will return to the question of whether these predictively equivalent explanations are equally good explanations. If, on the other hand, likelihood of truth is not simply a matter of evidential support, they may not be predictively equivalent. For there may be some beliefs which are likely to be true, but are not so because they are supported by evidence. If there are, the simple veritist explanans will predict that these are justified; the simple evidentialist explanans will not. The simple evidentialist explanans gets these cases right, while the simple veritist explanans 
gets them wrong-or so it seems to me. And one needn't be an evidentialist about justification to agree that the veritist explanation will be worse here. It will be enough if one thinks that justification requires evidential support. On that assumption, the evidentialist explanans will in this case explain better than the veritist explanans. ${ }^{5}$

The same dilemma will generalize to the other explananda. Where evidentialist explanations about rational belief, well-based belief, and knowledge are predictively equivalent to particular veritist explanations, the evidentialist explanations will be no worse than those veritist explanations. That is the first horn of the dilemma. On the other hand, where those veritist and evidentialist explanations come apart, those evidentialist explanations will often be better, and at any rate no worse. This is the second horn of the dilemma.

This second horn is dialectically difficult for both the veritist and the axiological evidentialist, because arguments that either explanation is better will rely on substantial assumptions about justification, rationality, basing, or knowledge. The example above made use of the substantive assumption that justification requires evidential support. This article is not the place to argue for that assumption or any other substantive assumption about justification, rationality, basing, or knowledge, any more than a paper on metaethics would be the place to argue for substantive claims in normative ethics. Still, it is a dialectical weakness of the present paper that its argument will not compel agreement from some groups of readers. This weakness is for four reasons less significant than it might seem.

First, the substantial assumptions about the role of evidence in epistemology will be broadly plausible. Evidentialists about justification will clearly accept the assumption in the example above. But one need not be an evidentialist to accept the assumption, since it articulates only a necessary condition on justification, rather than the biconditional which evidentialists articulate. ${ }^{6}$ Given how central most epistemologists take evidence to be to epistemology, it is quite plausible that the best evidentialist explanations will at least be no worse than the best veritist explanations, when these are not predictively equivalent.

Second, many readers who are not committed to these substantive assumptions will also not be committed to their negations. For instance, many readers who do not accept the claim that justification requires evidential support will suspend judgement about the claim, rather than positively rejecting it. Such readers should either think that neither veritism nor evidentialism explains better in virtue of divergent predictions, or they should suspend judgement about whether one theory explains better in these cases. In either case, even if they are not compelled to accept the claim that the veritist explanations are no better than the evidentialist explanations, they should also not reject it. Veritists who fall in this camp should seek an advantage for veritism elsewhere.

Third, even some readers who positively reject particular substantive assumptions should nonetheless not reject the claim that veritist explanations are no better. The reason is that, just as axiological evidentialists are not committed to evidentialism about

\footnotetext{
${ }^{5}$ In fact the assumptions required are weaker. The evidentialist explanations will be better provided that (1) it is even a general (but not exceptionless) requirement that justified beliefs are supported by evidence, while (2) likelihood of truth does not even in general require evidential support. Quantitatively formulated, the assumption would be weaker still.

${ }^{6}$ E.g. Conee and Feldman (2004, p. 83).
} 
justification, so they are not committed to any determinate set of substantial assumptions about justification (etc.). For instance, sophisticated axiological evidentialists might explain why some justified but evidentially unsupported beliefs are justified by citing other relations to evidential support: respect for evidence, tendencies to seek out evidence or to evaluate evidence fairly, and so on. Thus, many readers who reject particular substantial assumptions which might favor evidentialism should still suspend judgement about whether veritist or evidentialist explanations are on the whole better when they make divergent predictions-and so will also have to seek putative advantages for veritism elsewhere.

Fourth, there will be few readers who are positively convinced that the correct theories of justification (etc.) actually favor veritism, and so want to embrace this second horn. Such readers might think, for instance, that even those clairvoyants have justified beliefs who not only have no evidence for their belief, but would neither respect it if they did nor seek it if they could (etc.). Moreover, these readers will be dialectically no better off than axiological evidentialists. It is hard to imagine that they would have much success arguing for veritism on the basis of cases like this extreme clairvoyant case. And to the extent that their theories of justification are in fact grounded on veritism, they will actually be in a significantly worse dialectical position than the axiological evidentialist, who need not rely on their metaepistemological views to argue for a theory of justification.

In comparison, the first horn of the dilemma seems more promising for the veritist. Indeed, Pettigrew (2016) seeks to show that veritists can give the same range of explanations which axiological evidentialists can. If that could not be done, that would on his account ground an objection to veritism: ${ }^{7}$ "the veritist must show that certain evidential principles follow from her value monism" since otherwise it would be objected "that it cannot account for certain evidential principles." 8 That objection would however not be an objection to the claim that truth is a fundamental epistemic value; it is an objection to the claim that truth is the only epistemic value. By responding to it, Pettigrew is arguing for veritism rather than pluralism, but he is not thereby arguing for veritism rather than axiological evidentialism. Indeed, Pettigrew simply assumes that "having accurate credences is a good thing; accuracy is an epistemic virtue of a doxastic state." 9

Veritists who embrace the first horn of the dilemma will have to argue that veritist explanations are better than, although predictively equivalent to, evidentialist explanations. Pettigrew offers a nice illustration of this strategy, because he explicitly aims to give veritist derivations of evidential norms. If this project is successful, then the relevant veritist and evidentialist explanations will be predictively equivalent. But—so the

\footnotetext{
7 Pettigrew (2016) is of course concerned with credence rather than full belief, and with broadly-speaking evidential principles about credences (e.g. probabilism) rather than evidential principles about beliefs. These very important differences are suppressed here as irrelevant to the present argument.

8 p. 10.

${ }^{9}$ Pettigrew takes the assumption to be uncontroversial (p. 6), but points to Feldman and Conee (2004) as dissenters (fn. 4). Though I would be happy to have company in disputing that assumption, Feldman (2004a) seems unlikely company, since he writes: "Whatever our goals, it makes sense to suppose that believing truths (or some related state) has epistemic value, that it is a good thing from an epistemic point of view." (p. 182).
} 
veritist may argue - the veritist explanations will be more fundamental, and so better explanations after all. Suppose that we can derive some set of evidential norms from veritist norms, as Pettigrew proposes to do. Suppose also that these derivations are explanatory, so that the veritist norms potentially explain the evidential norms. The resulting veritist explanations would plausibly be better than explanantions which began from those evidential norms, without derving them from further norms.

But it would not follow that veritist explanations were better than evidentialist explanations. For axiological evidentialists can also derive these evidential norms from more fundamental norms-more fundamental evidentialist norms. For instance, norms for things other than belief can be explained as ways of valuing evidential support. Why do we generally have reason to investigate some questions rather than others? Plausibly, because letting our evidence guide what we investigate is a way of respecting the value of evidential support. ${ }^{10}$ Investigating questions where we already have robust evidence which strongly supports an answer is ceteris paribus a way of not valuing the evidence we already have, while investigating questions where our present evidence is less robust, or does not strongly support a determinate answer, is a way of respecting evidence we do not yet have. In the same way, believing what our evidence supports is a way of manifesting respect for the value of evidential support. So the axiological evidentialist is free to explain evidential norms for belief and for investigation in terms of more fundamental principles, rather than taking them to be brute facts. Indeed, they should - for by doing so, they will remove one ground for thinking that veritist explanations are better because deeper.

There is another way veritist explanations might be better than evidentialist explanations, although they are predictively equivalent when it comes to these uncontroverisially epistemic evaluations. If the veritist explanations also cover cases which the evidentialist explanations do not, then they will be more unifying, and so plausibly better. These cases will have to go beyond the uncontroversially epistemic explananda considered so far. Not coincidentally, the only arguments for veritism of which I am aware take veritism to enjoy just this kind of advantage: in addition to explaining evidential norms, veritists are supposed to be able to explain accuracy norms, or explananda about accurate belief. So, in the next section, I'll turn to these arguments.

After doing so, I'll also be in a position to respond to an objection. The objection is that, since knowledge is factive, evidentialist explanations of the knowledge explananda will have to make use of truth in the explanans, as the simple explanantia above do. This looks like an illicit mentioning of a distinct epistemic value in the evidentialist explanans. But, at the end of the next section, I'll argue that the axiological evidentialist need not make use of truth in their explanations of knowledge explananda.

\section{Best explaining evaluations: not epistemic}

Veritism might be thought to get an explanatory edge because it can explain, and evidentialism plausibly cannot, our pro tanto reasons to desire beliefs. It is to these that veritists commonly point when explaining why veritism is plausible. Consider

\footnotetext{
10 For this reason, Feldman is too quick to deny that we have epistemic duties to look for evidence; cf. fn. 20 below.
} 
Ahlstrom-Vij and Grimm's summary statement of the main reason to believe that truth is the only fundamental epistemic value:

Because it seems that our ultimate goal as epistemic agents is to have beliefs that are true, and that to the extent that we want our beliefs to have other features to be rational, or justified, or based on good evidence, for example - this is only because we think these other features will make it more likely that our beliefs are true. ${ }^{11}$

Whatever its other merits, I contend that this argument contains a generally overlooked non sequitur. ${ }^{12}$ In particular, the evaluation explained is not an epistemic evaluation.

So, for all I say here, the following evaluations may be true:

"we generally have pro tanto reason to desire rational (or justified, etc.) beliefs"

Moreover, the best explanation of that claim may well be truth-centric, i.e. that we generally value true beliefs or things which make it more likely that our beliefs are true. These claims matter to debates about why evaluations about justified belief have categorical normative force, because those debates are about what we have reason to desire. But the present question is not about categorical normative force, or reasons to desire. It is instead about epistemic value.

For questions about epistemic value, it matters very much whether this evaluation, and the pro tanto reason mentioned in it, are epistemic. If they are not epistemic, then these evaluations will be simply irrelevant to the question, and so of no help to the veritist. And, I contend, these evaluations are not epistemic. For the reason involved is a reason to desire to have certain beliefs: a paradigmatic pragmatic reason for belief, of the kind involved in Pascal's wager. And surely no-one would count as epistemic other paradigmatically pragmatic evaluations, e.g.

"we generally have pro tanto reason to desire to believe whatever garners us infinite payoff"

Since these evaluations are not epistemic, explanations of them are simply irrelevant to epistemic values. More to the point, veritism would not give more unifying explanations of epistemic evaluations in virtue of explaining these evaluations, since they are not epistemic.

The same problem extends to simpler cases, like explananda involving the truth of beliefs. It is extremely plausible that truth explains the correctness of beliefs; at any rate, it is significantly more plausible than that truth explains the correctness of desires, hopes, bets, and suppositions for the sake of argument. So suppose that truth best explains the evaluations

"S's belief that $\mathrm{p}$ is accurate"

"S's belief that $\mathrm{p}$ is true"

\footnotetext{
11 Ahlstrom-Vij and Grimm (2013), p. 329 (emphasis mine), echoing arguments in David (2005) and BonJour (1985).

12 Though Ridge (2013) makes the related point that the distinction between predicative and attributive goodness is neglected in arguments like these.
} 
Would it follow that truth was a fundamental epistemic value? No. For there is no reason to suppose that these evaluations are epistemic. Indeed, there is reason to deny that these evaluations are epistemic evaluations. For that judgement patterns with clearly correct judgements about similar evaluations, such as evaluations of beliefs as beautiful, felicitous, fruitful, or instrumentally good for forming further true beliefs [as in the case central to Firth (1981)]. None of these are epistemic evaluations. ${ }^{13}$

Some apparently similar evaluations may be epistemic, but will not help the veritist:

"S's guess that $p$ was accurate"

"S's guess that p was lucky"

"S's belief that p was a lucky guess"

The best explanations for these evaluations may well even be truth-centric. But, to the extent that they are epistemic evaluations, they are negative evaluations. They say that a certain belief that $\mathrm{p}$ was merely a guess, or that it was lucky, and so was neither knowledge nor justified. To the extent that luck or guessing is a good thing, it is good because it serves our practical interests. On the other hand, to the extent that luck or guessing is an epistemic thing, it is a bad thing. So even if these evaluations are epistemic and the best explanations of them are truth-centric, veritist explanations would get their valence wrong: would count them as epistemically positive, when they are epistemically negative.

So veritism does not get an explanatory advantage in either of two places it might be thought to. It does not get an explanatory advantage in virtue of explaining our reasons to desire evidentially supported beliefs, for these are not epistemic evaluations. Nor does veritism get an edge by explaining evaluations of beliefs as accurate, since in most cases these are not epistemic evaluations. When evaluations of beliefs as accurate are epistemic, they are not positive insofar as they are epistemic. In short: true beliefs are clearly of value. But they are not of epistemic value. That is not to assume the falsity of veritism, for veritists need not say that true beliefs are themselves of epistemic value; indeed, given that these evaluations are not epistemic, veritism should not say that. Being true is not bearing the right kind of relation to truth for beliefs to be of epistemic value.

This grounds a reply to the objection at the end of the last section, that evidentialist explanations of the knowledge explananda will have to make illicit use of truth in their explanans. The reply is that, once we have properly demarcated the epistemic explananda, there is no need for the evidentialist to mention truth in the explanans. The crucial point is that the uncontroversial explananda about knowledge, though they were earlier formulated simply in terms of "S knows p," are better formulated as "S's true belief that $\mathrm{p}$ amounts to knowledge." 14 The mention of truth in those explananda

\footnotetext{
13 Veritists in the usual usage of the term, who think that truth is the only fundamental epistemic value, will have additional reason to count true beliefs as not themselves of epistemic value. As Bjelde (2019) argues, monist veritists must either deny that true beliefs are themselves of epistemic value, or deny one of two extremely plausible claims, either that (1) justified false beliefs are epistemically better than unjustified true beliefs, or that (as Sylvan does) (2) fundamental values outweigh derived values.

14 This line of response is strictly parallel to a response one might have about the justification explananda in the face of pragmatic encroachment. One might say: it's not strictly speaking "S's belief that p is justified" which is the epistemic explanandum, but some related evaluation which is not sensitive to pragmatic facts.
} 
is no more problematic than the mention of belief, since neither truth nor belief need be mentioned in the explanans. And explanada that mention truth, including the type level explanandum that "knowledge is factive," will as a rule be no more epistemic than "knowledge is beautiful" or that "knowledge is required to justify action." Since those are not epistemic evaluations, they need not be explained by an epistemic axiology. In the same way, "knowledge is factive," though it is true, is simply not an epistemic evaluation, and so also needs no explanation by an epistemic axiology.

\section{Best explaining epistemic evaluations: but not true}

A similar objection might, however, be inspired by Turri (2016). Where the objection above was restricted to knowledge, this objection claims that we will have to cite truth in the explanans even of the uncontroversial explananda about non-factive states, because these evaluations turn out to be truth-sensitive. Turri investigates a broad variety of such uncontroversially epistemic evaluations, but I'll focus on the most difficult one for the present argument:

"S's evidence justifies $S$ in believing p"

Turri's claim is that these evaluations are sensitive to the truth of $\mathrm{p}$ in the mouths of ordinary folk. So his conclusion is about ordinary evaluative practice. But Turri's data might naturally be taken to support a claim not about the evaluative practice of ordinary folk, but about correct evaluative practice, namely that epistemic evaluations like this one are truth-sensitive. They are truth sensitive in the sense that two believers, S1 and S2, who enjoy the same degree of evidential support for their beliefs, can come apart with respect to justification, depending on the truth of p. Put another way, the point is that the truth of $\mathrm{p}$ is an independent factor in predicting and explaining these evaluations. In particular, it is sometimes true that S1's evidence justifies S1 in believing $\mathrm{p}$, because $\mathrm{p}$ is true (relative to S1's context), but S2's evidence does not justify S2 in believing $\mathrm{p}$, because $\mathrm{p}$ is false (relative to S2's context). ${ }^{15}$ Whether or not truth is the sole value to play an explanatory role in explaining that (putative) fact, it will certainly play $a$ role.

In outline, Turri's data about this kind of evaluation is as follows. Ordinary folk were assigned to read a description of a situation in which a believer has some evidence for a belief, but some of the folk were in addition told that $\mathrm{p}$ was false, while others were told that $\mathrm{p}$ was true. Those told that $\mathrm{p}$ was true were significantly more likely to agree to evaluations like the one above. So it seems that the epistemic evaluative practice of ordinary folk is sensitive to the truth of $\mathrm{p}$. If that ordinary evaluative practice is correct, it would follow that these epistemic evaluations are sensitive to the truth of $\mathrm{p}$.

Gerken (2020) gives a way to resist this last step. Even while granting Turri's claim that the evaluative practice of ordinary folk is truth sensitive, Gerken argues that this evaluative practice is a result of outcome bias. The basic thought is that the evaluative practices of ordinary folk are skewed so that they retrospectively evaluate things which lead to positive results more highly than those which lead to negative results. That is

\footnotetext{
15 For the sake of simplicity, I am suppressing several details about Turri's data which do not affect the argument.
} 
a plausible way to account for Turri's data, and ordinary evaluative practice, without granting that correct epistemic evaluations really are truth sensitive.

But, for related reasons, it is not clear that we should grant Turri's claim about the evaluative practice of ordinary folk. It is true that, if the evaluative practice of ordinary folk were truth sensitive, that would explain Turri's data. But alternative explanations seem quite plausible. Even supposing that someone is not subject to outcome bias, they are certainly subject to error when they extrapolate from very meager information. Turri's subjects are told so little about the believers in question, that it seems quite reasonable of them to fill out the characterization with the information about outcomes they are given. Consider Turri's Maria:

Maria is a watch collector who owns over ten thousand watches. She cannot keep track of all her watches by memory alone, so her accountant maintains a detailed inventory of them. Maria knows that the inventory isn't perfect, but it is extremely accurate. Someone asks Maria, "Do you own a 1990 Rolex Submariner?” Maria consults the inventory and it says that she does have one. In fact, she [does/does not] have one. ${ }^{16}$

If asked whether Maria's evidence justifies belief in her answer, it would be reasonable to take into account not only the general information about the accuracy of the inventory, but also the specific information provided about whether Maria does or does not get it right in this case. If Maria does not have the watch, but believes she does, that is some evidence that she is unreliable, and it is in addition some evidence that Maria's evidence doesn't justify her beliefs. In general, our evaluations of whether other believers are justified are formed on the basis of evidence which far outstrips what is said about Maria in the sample passage. So it would be surprising if study participants did not use the additional bits of information given-about whether Maria's beliefs are true-as evidence relevant to assessing whether Maria's belief is justified on the basis of her evidence. For this reason, too, Turri's data do not support the claim that epistemic evaluations are truth sensitive.

So the results of the earlier sections stand. On the very plausible assumption that veritism does not get an explanatory edge in virtue of predictive divergences about the uncontroversially epistemic evaluations, veritism has no edge when it comes to those uncontroversially epistemic evaluations. And since, as I contended in Sect. 3, the only other evaluations where veritism might get an explanatory edge fail to be epistemic, it follows that veritism has no explanatory edge. That is, there are no epistemic evaluations which truth best explains. It follows that truth is not an epistemic value.

\section{Bounding the epistemic}

Why have so many philosophers thought that truth is a fundamental epistemic value? I suspect that there are two major reasons. The considerations cited by Ahlstrom-Vij and Grimm along with many others are one major reason. But those considerations

16 Turri (2016, p. 351). 
support a conclusion about what plays a fundamental role in explaining what we desire and have reason to desire, rather than explaining epistemic evaluations. So those considerations are not probative for whether truth is a fundamental epistemic value. To treat them as probative is, it seems to me, to confuse the practical with the epistemic.

But another major reason is a kind of conception of what marks the boundaries of the epistemic, however vague those boundaries may be. So, for instance, Pritchard (2013) asks "isn't it simply characteristic of the epistemic that it is directed at truth?" And Alston (2005) writes that

'Epistemic' will require more explanation [than 'evaluation']. We evaluate something epistemically... when we judge it to be more or less good or bad from the epistemic point of view, that is, for the attainment of epistemic purposes. And what purposes are those? We can best approach this question by reminding ourselves that epistemology consists of a critical reflection on human cognition. And the evaluative aspect of epistemology involves an attempt to identify ways in which the conduct and the products of our cognitive activities can be better or worse vis-a-vis the goals of cognition. And what are those goals? Along with many other epistemologists I suggest that the primary function of cognition in human life is to acquire true rather than false beliefs about matters that are of interest or importance to us. ${ }^{17}$

Alston's thought is twofold: first, that epistemic evaluations are about good and bad cognition, and second, that cognition counts as good when it serves the function of acquiring true beliefs. So the pursuit of the truth is what marks out epistemic evaluations as epistemic, according to Alston. This conception of the epistemic would naturally lead one to count as epistemic those evaluations of beliefs as accurate or true which I earlier contended were not epistemic. So the widespread appeal of veritism is perhaps best understood in terms of this conception of the boundaries of the epistemic.

But there is another influential view about the boundaries of the epistemic, according to which it is evidential support rather than truth which marks them out. So, for instance, in the debate about pragmatic encroachment, it is common to distinguish properly epistemic from pragmatic factors in justification, and to do so along the following lines. The evidential support for a belief is a properly epistemic factor in the justification of the belief. The importance of getting it right is not an epistemic, but a pragmatic factor. ${ }^{18}$ In a similar way, evidence also plausibly marks the distinction between properly or narrowly epistemic questions about skepticism from semantic questions about the meaning of "knows," as Feldman describes them:

The debate about skepticism is thus seen not as a debate in which the quality of our evidence is agreed to and the debate results from differing views about what the standards for knowledge are. Instead, it is a debate about how good

\footnotetext{
17 Alston (2005, p. 29).

18 As in the locus classicus for the debate: Fantl and McGrath (2002). Note that, for all I say here, pragmatic factors might encroach also on evidential support. So the present point is not that pragmatic factors can't play a role in properly epistemic evaluations. It's just that factors other than evidential support will not be epistemic factors.
} 
our evidence is. Understood that way, it is difficult to see the epistemological significance of decisions about which standards are associated with the word 'knows' in any particular context. ${ }^{19}$

One might take Feldman's point here narrowly, to distinguish epistemic and nonepistemic factors involved in ascriptions of knowledge. But an equally reasonable way to understand Feldman has him making a general claim about how to draw the boundaries of the epistemic. That general claim extends beyond knowledge ascriptions to epistemic evaluations in general, and so demarcates the properly epistemic values. ${ }^{20}$

Whether the boundaries should be drawn in this Feldmanian way or otherwise is of course a substantive question of its own, which I will not try to settle here. Indeed, it is not clear to me how to argue for a particular way of bounding the epistemic. Nor, Alston writes, does he know how to argue the point, since he doesn't "know anything that is more obvious from which [his claims quoted above] can be derived." 21 Still, that doesn't stop him from suggesting that others can "see its obviousness" if they reflect on the of practical advantages of true beliefs over false beliefs. As the reader may by this point guess, those practical advantages seem to me simply irrelevant to epistemology. Whether the Feldmanian can do any better by way of persuading their opponents is not clear to me, but I imagine that they might say something like the following.

Theories of truth have no place in an introductory epistemology course. By contrast, theories of moral goodness are not out of place in an introductory ethics course, and theories of beauty are not out of place in an introductory aesthetics course. The reason for this difference is not far to seek. It is that epistemology is not concerned with truth, although it is concerned with evidence, and evidence is evidence of truth. Naturally, there are other connections between truth and evidence. For instance, evidence plausibly makes truth in some sense likely. But questions about these connections are like questions about the relation between epistemic obligations and moral obligations: they are questions that cut across subdisciplines. In the one case, the questions are about the relations between epistemic and ethical subject matters. In the other, the questions are about the relation between an epistemic subject matter and the truth. But these connections do not bear on what epistemology is about. So they do not show that epistemology is about truth.

Moreover, the Feldmanian is at an advantage in answering these intersubdisciplinary questions. For instance, it is clearly an important question just how epistemic values relate to practical values, and in particular to the practical value of true beliefs and knowledge. On Alston's way of bounding the epistemic, the answers to these questions largely falls out of what it is to be an epistemic evaluation. That seems to me to put the cart before the horse: to stipulate too much of answer to a question which deserves a non-stipulative answer. The Feldmanian way of bounding the epistemic has the advantage that doesn't put that particular cart before the horse.

${ }^{19}$ Feldman (2004b, p. 32); emphasis mine.

20 That this is a reasonable way to understand Feldman is witnessed by his willingness to characterize duties to seek evidence as "moral and prudential issues" (Feldman 2004a, p. 189).

21 Alston (2005, p. 30). 
Some readers may be inclined to wash their hands of this boundary dispute. If they nonetheless count evaluations of beliefs as accurate or true as epistemic evaluations, or if they suspend judgement about whether those evaluations are epistemic, the present argument will not compel them to agree that veritism is false. Likewise, some readers may embrace the second horn of the earlier dilemma, and claim that veritism better explains cases like the extreme clairvoyant case earlier. The present argument also does not compel their agreement. It does, however, show that such readers need to do more to motivate veritism, if they are inclined to advocate it.

Feldmanian readers, on the other hand, should grant that evaluations of beliefs as accurate or true are not epistemic evaluations, since those evaluations say nothing about any relation to evidence. And they should grant that, where veritist explanations make divergent predictions about justification, for instance because they capture relations to the truth which are in no way mediated by evidence, the evidentialist explanations will be at least as good. And those who grant these plausible assumptions, Feldmanians or not, should also grant what follows. Truth does not best explain any specifically epistemic evaluations. So truth is not of fundamental epistemic value. ${ }^{22}$

Acknowledgements Open Access funding provided by Projekt DEAL.

Funding This work was supported by the Zukunftskonzept of the Humboldt Universität zu Berlin in connection with the Exzellenzinitiative von Bund und Ländern [projektnr. 0191 0136-26].

Open Access This article is licensed under a Creative Commons Attribution 4.0 International License, which permits use, sharing, adaptation, distribution and reproduction in any medium or format, as long as you give appropriate credit to the original author(s) and the source, provide a link to the Creative Commons licence, and indicate if changes were made. The images or other third party material in this article are included in the article's Creative Commons licence, unless indicated otherwise in a credit line to the material. If material is not included in the article's Creative Commons licence and your intended use is not permitted by statutory regulation or exceeds the permitted use, you will need to obtain permission directly from the copyright holder. To view a copy of this licence, visit http://creativecommons.org/licenses/by/4.0/.

\section{References}

Ahlstrom-Vij, K., \& Grimm, S. (2013). Getting it right. Philosophical Studies, 166, 329-347.

Alston, W. (2005). Beyond 'justification': Dimensions of epistemic evaluation. Ithaca: Cornell UP. Bjelde, J. (2019). All swamping, no problem. Analysis. https://doi.org/10.1093/analys/anz061.

BonJour, L. (1985). The structure of empirical knowledge. Cambridge: Harvard UP.

Conee, E., \& Feldman, R. (2004). Evidentialism: Essays in epistemology. Oxford: OUP.

David, M. (2005). Truth as the primary epistemic goal. In M. Steup \& E. Sosa (Eds.), Contemporary debates in epistemology. Oxford: Blackwell.

Fantl, J., \& McGrath, M. (2002). Evidence, pragmatics, and justification. The Philosophical Review, 111(1), 67-94.

Feldman, R. (2004a). The ethics of belief. In Conee and Feldman 2004.

Feldman, R. (2004b). Comments on DeRose's single scoreboard semantics. Philosophical Studies, 119, 23-33.

\footnotetext{
22 Thanks are due first and foremost to John MacFarlane, who first asked me why one should think that truth is an epistemic value, though he bears no responsibility for the heretical answer to that question which I defend here. I am also grateful for probing questions and comments from Jim Hutchinson, Branden Fitelson, Jonathan Beere, Sarah Broadie, several anonymous reviewers, and the editors of this issue.
} 
Firth, R. (1981). Epistemic merit, intrinsic and instrumental. Proceedings and Addresses of the American Philosophical Associations, 55(1), 5-23.

Gerken, M. (2020). Truth-sensitivity and folk epistemology. Philosophy and Phenomenological Research, $100(1), 3-25$.

Pettigrew, R. (2016). Accuracy and the laws of credence. Oxford: OUP.

Pritchard, D. (2014). Truth as the fundamental epistemic good. In J. Matheson \& R. Vitz (Eds.), The ethics of beliefs. Oxford: OUP.

Ridge, M. (2013). Getting lost on the road to Larissa. Noûs, 47(1), 181-201.

Sylvan, K. (2018). Veritism unswamped. Mind, 127, 381-435.

Turri, J. (2016). The radicalism of truth-insensitive epistemology: Truth's profound effect on the evaluation of belief. Philosophy and Phenomenological Research, XCII(2), 348-367.

Publisher's Note Springer Nature remains neutral with regard to jurisdictional claims in published maps and institutional affiliations. 